\title{
'Hakuna matata': a volunteer's adventure
}

Please send any ideas for feature articles for consideration to:

Rowena Milan,

British Dental Journal,

The Macmillan Building

4-6 Crinan Street,

London

N1 9XW

Email:r.milan@nature.com

\section{S. Ernst}

BDS, SHO in Oral and Maxillofacial Surgery,

Royal Gwent Hospital, Newport, South Wales

simon.ernst@gmail.com

When Simon Ernst decided he wanted to work for six months as a volunteer dentist in Africa, he expected to spend all his time working in one place. Instead he found himself organising the trip of a lifetime, working with three different organisations in three different African countries. Here is describes some of the lows of the planning process, and the extraordinary highs he experienced once he arrived.

When I started planning this adventure, I did not realise just how incredible it would be. Volunteering in three different African countries, working with different organisations providing and facilitating the provision of dental care, I found that the people, the places and the culture touched and enriched me in ways I cannot describe.

I started out with the simple idea of volunteering in Africa. I cannot say what my specific motive was, only that it was something I had always dreamt of doing. There was something mysterious about Africa that had always appealed to me, perhaps the raw nature of it. I chose a time period of six months immediately after vocational training, at a time where commitments were not yet tying me down.

I then began my search for organisations on the internet and although lots of search results come up when one types in words such as 'volunteering' and 'dentist', if you take the time to follow them up, there appears to be relatively little work available in Africa. Medical organisations would often place a dental link on the website but not put any information in it; larger organisations such as VSO and Médecins Sans Frontiers required more experience and training than I had. I had already decided that working on Mercy Ships was not for me and while there were American-based non-governmental organisations that

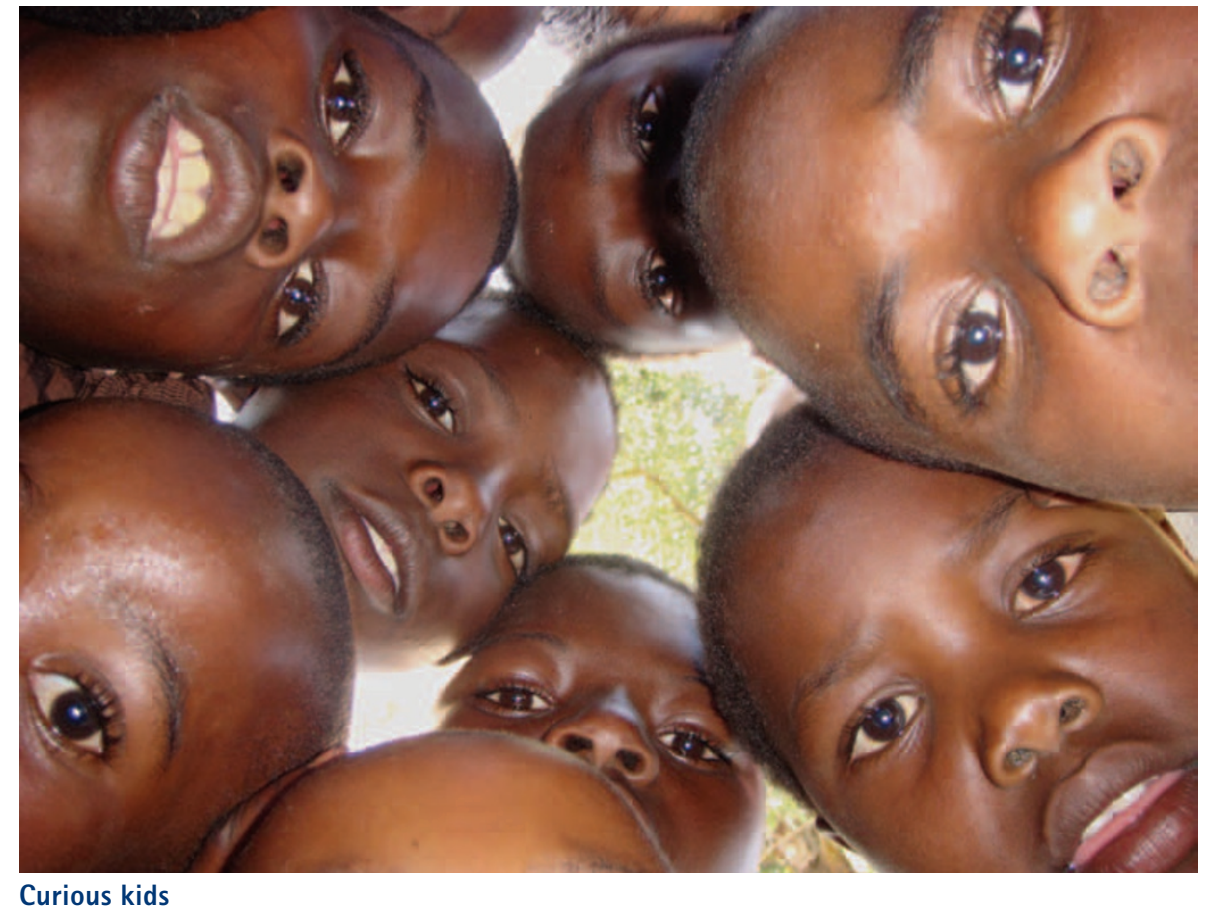

wanted people in South America, I was insistent on Africa. I had thought it would be easy: why would anyone not want a UK qualified dentist willing to come out and work for free?

\section{A final push}

By April 2007, a mere four months short of my proposed leaving date, I had still not received a single positive reply. I had been looking for eight months now and was beginning to lose hope. I was resigned to the fact that, come the end of April, if I still had no invitations to work in Africa I would be forced to look for a job in the UK. I sent a last barrage of emails imploring for work and then waited and hoped.

Two weeks later, two days short of the cut-off date I had set myself, I received three different invitations from three different organisations in three different countries in Africa! The first was from Dr Ian Wilson of Bridge2Aid (B2A), based in Mwanza, Tanzania. He was excited about the prospect of me working for a couple of months but was also worried about what experience I had and 
how I would cope in an African environment. My referees and I reassured him that I was as eager and ready as I would ever be. The second invitation came from Dr Chris Barton at the Rugarama Health Centre in Kabale, Uganda. Being a former vocational trainer and as he regularly supervises Bristol dental students on electives, he was more familiar with my level of training and was very grateful for my interest and willingness to help. The third invitation came from the unlikely source of a Dr Ahmed Adam, Medical Director of the Government District Hospital in Hlabisa, South Africa. My details had somehow been passed on to him and he was only too happy to receive me, regardless of experience.

Fantastic, I thought, the rest will be easy. How wrong could I have been? Before me now was the task of filling out all the paperwork, applying for visas, work permits, inclusion on local medical boards, and tying up loose ends back here in the UK. I was also embarking on further examinations before I left so as to improve my chances of obtaining a job for my return. All this while working longer hours to earn as much money as possible to see me through the six months. By the time I was ready to leave for Mwanza, my first port of call, I was ready for a holiday!

It had been a seriously stressful final four months but I was ready to take on whatever was thrown at me. The time had come to depart so with great difficulty and many tears I said my goodbyes to my partner and, both eagerly and apprehensively, headed off into the unknown.

\section{The adventure begins}

Africa was alive with sounds, colours and scents all day and night. It was a truly surreal experience, with constant music, church bells, and calls for prayers from mosques. Drums were rumbling, people were singing, crickets were chirping, dogs were barking, cows were mooing - the sounds appeared to be coming from everywhere! The clothing was fascinating with bright, vibrant colours and patterns that would seem out of place in the UK. The people were friendly and always smiling, big white

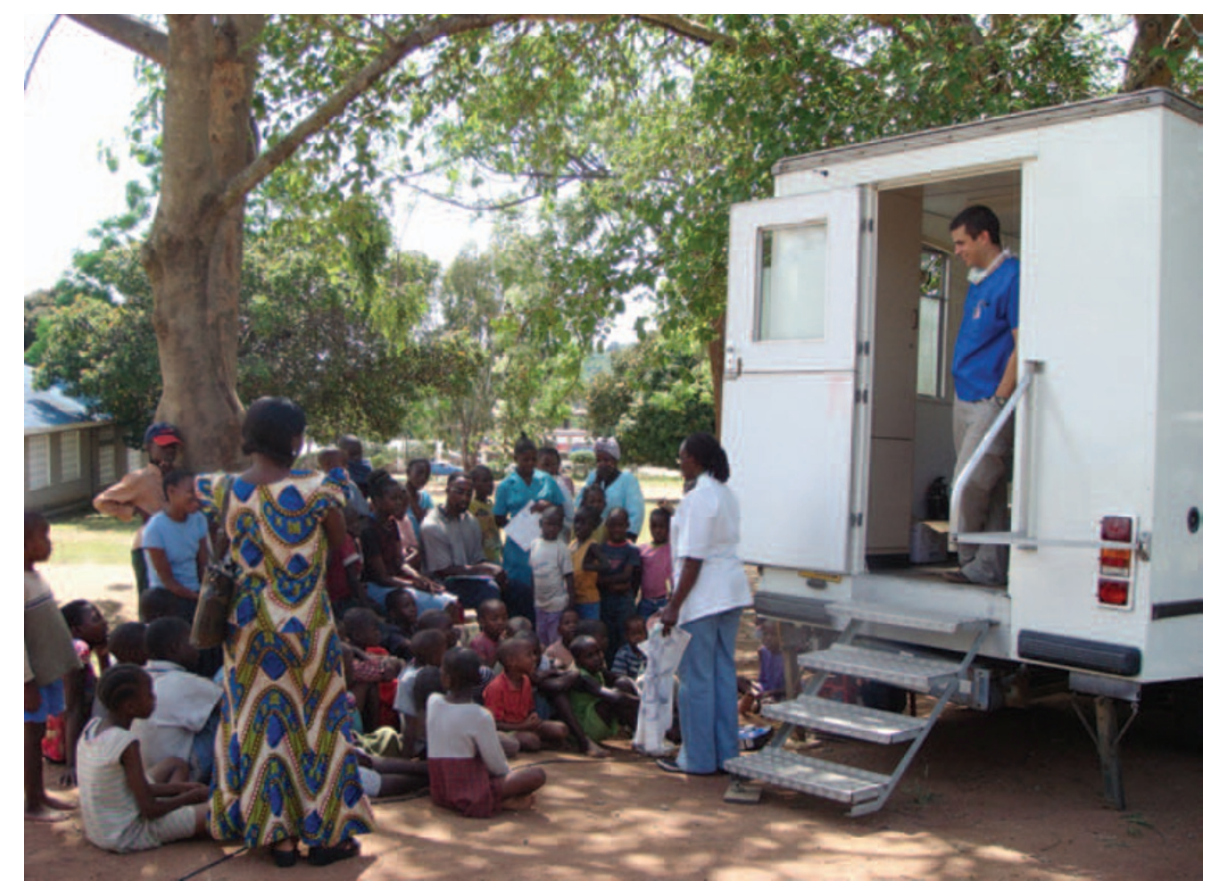

Outreach teaching and screening in Mwanza

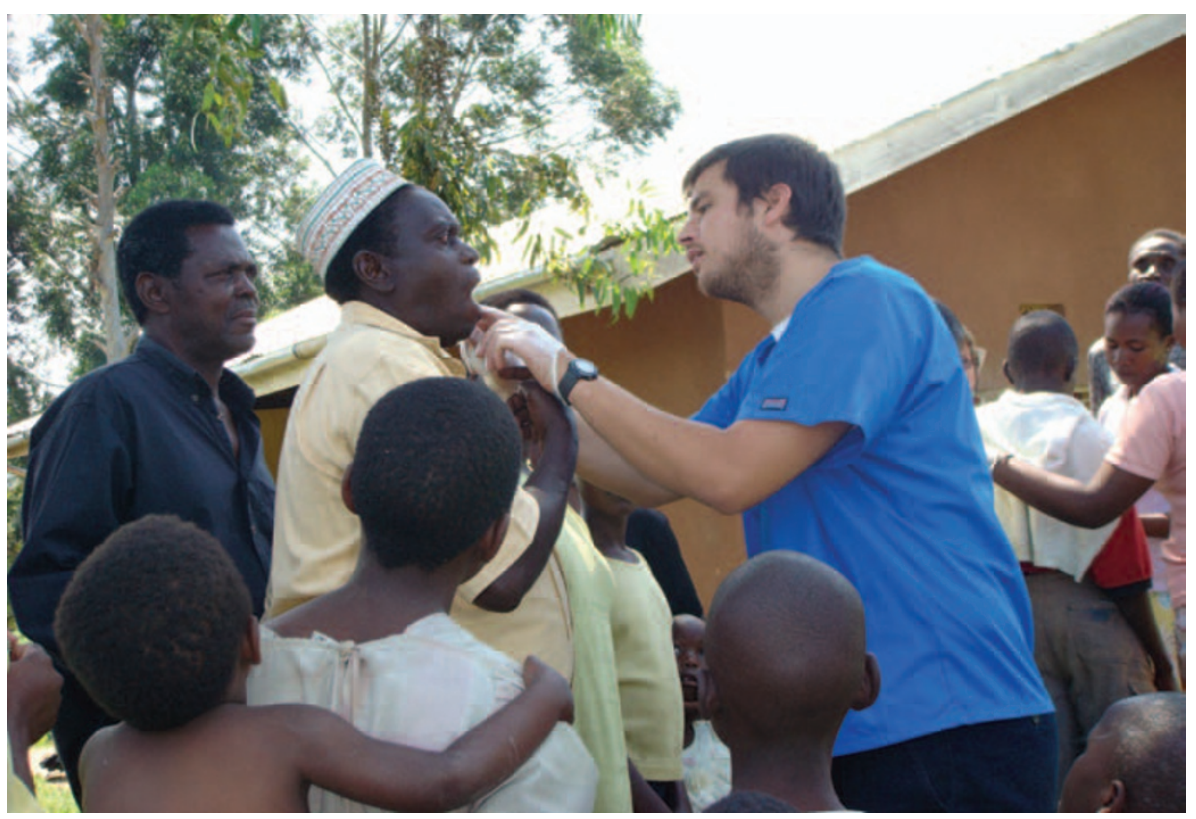

Which tooth hurts?

smiles with the odd missing front tooth.. It struck me that in the face of all the socio-economic adversities, these people were still happy.

I was surprised to find that in Mwanza, the work was very similar to that carried out in any NHS practice back home, which meant that adapting was easier. I was there to manage the clinic, giving Ian the freedom to work with the rest of the $\mathrm{B} 2 \mathrm{~A}$ team on other projects and fundraising exercises. The obvious language barriers proved challenging, but with the help of everyone around, especially the nursing staff, I was able to just about get by. I was also there to provide a 'flying dentist' service to some of the gold mines in the area, flying in tiny four-seater Cessna aircraft and landing in the middle of nowhere on gravel runways.

$\mathrm{B} 2 \mathrm{~A}$ is involved in improving the standards of living and oral health in the more impoverished communities in Mwanza. They dedicate much of their time to surrounding schools, orphanages and the 'Maskini' (homeless people on the streets of Mwanza). Their main projects are improving the standards of living for a leper community just outside 
the city, and using UK-based dental volunteers to provide clinical officer training in emergency dentistry for deep rural areas during residential courses.

The whole team really loved what they were doing and that enthusiasm and drive to go further, do more and impact on more people was contagious. It was clear that the locals appreciated their presence and valued all that was being done.

\section{Kabale and Hlabisa}

Work in Kabale was to be completely different from Mwanza: I was there to teach. Two locally trained clinical dental officers, similar to dental therapists, saw most of the patients in the Dental Department at Rugarama Health Centre. I was there to supervise and advise them as was necessary and to help teach a course on oral health, simple exodontia and cross-infection control to local clinical officers. I had little previous experience in teaching until Kabale but found it remarkably rewarding.

Through much effort, funds and equipment donations, Chris and Polly Barton have been able to set up regular outreach visits to schools, churches and medical centres. This is essential as most people live in rural areas and are unable to travel to Kabale for treatment. Their projects also include setting up dental clinics in rural areas and arranging equipment, mainly through Dentaid. They then sponsor selected people to go to the capital, Kampala, and train as clinical dental officers to go and work at these rural clinics. Unfortunately their time in Kabale has now come to an end, but I am sure others will be in their shadows to pick up where they left off.

When I reached South Africa, my partner and fellow dentist, Katie Noble, joined me. We arrived in Hlabisa to find no preparation for our arrival. We therefore set about organising outreach visits to many different rural clinics, in the most basic of surroundings with the most basic of equipment. Treatment here consisted of extraction only and we were both shocked at the lack of facilities and oral health promotion campaigns in what was meant to be the most developed African country. We stressed the importance of this to Dr. Adam and he vowed to address the situation and implement the changes we suggested.

Hlabisa Hospital in the KwaZulu-Natal region of South Africa is run by the local health authority. They aim to develop a sustainable, co-ordinated, integrated and comprehensive health system at all levels based on the primary healthcare approach. This should be with local doctors and dentists, but due to a lack of local dentists and doctors willing to work in a rural hospital, Dr Adam is constantly looking abroad. He is in the process of supervising the build of a brand new hospital in Hlabisa and I am sure will be requiring more dentists and doctors than ever before.

\section{Returning home}

By the time we came to depart from Johannesburg for the UK, we were both melancholic. We were heading back to the UK to take up our lives where we had left off and while we were glad to be going home, at the same time Africa would be sorely missed. After all we had experienced, it was finally over.

Obviously this is only the tip of the iceberg when I think about this trip, the people I have met and the things I have seen. Whatever preconceptions you may have about Africa and working in Africa, it is a unique experience I strongly recommend to all ages, genders and professional grades, dentists and doctors alike. There is always something that can be done so long as there are people willing to sacrifice their time and energy. I dedicated much time and effort to this expedition and have no regrets. Hopefully I was able to impact on just a few lives the way that Africa made an impact on me.

For more information or to make a donation, please visit the following websites:

Bridge2Aid: www.bridge2aid.org

Rugarama: www.rugaramahospital.org

Dentaid: www.dentaid.org

Hlabisa Hospital: www.kznhealth.gov. za/hlabisahospital.htm

DOI: 10.1038/sj.bdj.2008.737 